\title{
Ventromedial Prefrontal Cortex Damage Is Associated with Decreased Ventral Striatum Volume and Response to Reward
}

\author{
๑Daia S. Pujara, ${ }^{1,2}$ Carissa L. Philippi, ${ }^{1,5}$ Julian C. Motzkin, ${ }^{1,2,4}$ Mustafa K. Baskaya, ${ }^{3}$ and ${ }^{\circledR}$ Michael Koenigs ${ }^{1}$ \\ ${ }^{1}$ Department of Psychiatry, ${ }^{2}$ Neuroscience Training Program, ${ }^{3}$ Department of Neurological Surgery, and ${ }^{4}$ Medical Scientist Training Program, University of \\ Wisconsin-Madison, Madison, Wisconsin 53705, and ${ }^{5}$ Department of Psychological Sciences, University of Missouri-St. Louis, St. Louis, Missouri 63130
}

\begin{abstract}
The ventral striatum and ventromedial prefrontal cortex (vmPFC) are two central nodes of the "reward circuit" of the brain. Human neuroimaging studies have demonstrated coincident activation and functional connectivity between these brain regions, and animal studies have demonstrated that the vmPFC modulates ventral striatum activity. However, there have been no comparable data in humans to address whether the vmPFC may be critical for the reward-related response properties of the ventral striatum. In this study, we used fMRI in five neurosurgical patients with focal vmPFC lesions to test the hypothesis that the vmPFC is necessary for enhancing ventral striatum responses to the anticipation of reward. In support of this hypothesis, we found that, compared with age- and gender-matched neurologically healthy subjects, the vmPFC-lesioned patients had reduced ventral striatal activity during the anticipation of reward. Furthermore, we observed that the vmPFC-lesioned patients had decreased volumes of the accumbens subregion of the ventral striatum. Together, these functional and structural neuroimaging data provide novel evidence for a critical role for the vmPFC in contributing to reward-related activity of the ventral striatum. These results offer new insight into the functional and structural interactions between key components of the brain circuitry underlying human affective function and decision-making.
\end{abstract}

Key words: decision-making; fMRI; lesion; prefrontal cortex; reward; striatum

\section{Significance Statement}

Maladaptive decision-making is a common problem across multiple mental health disorders. Developing new pathophysiologically based strategies for diagnosis and treatment thus requires a better understanding of the brain circuits responsible for adaptive decision-making and related psychological subprocesses (e.g., reward valuation, anticipation, and motivation). Animal studies provide evidence that these functions are mediated through direct interactions between two key nodes of a posited "reward circuit," the ventral striatum and the ventromedial prefrontal cortex (vmPFC). For the first time in humans, we demonstrate that damage to the vmPFC results in decreased ventral striatum activity during reward anticipation. These data provide unique evidence on the causal mechanisms by which the vmPFC and ventral striatum interact during the anticipation of rewards.

\section{Introduction}

The brain's "reward circuit" - the network of regions encoding various aspects of pleasure, motivation, and value-is a critical biological substrate underlying human emotion, decision-

\footnotetext{
Received Nov. 24, 2015; revised Feb. 29, 2016; accepted March 14, 2016.

Author contributions: M.S.P. and M.K. designed research; M.S.P. performed research; M.S.P., C.L.P., J.C.M., and M.K.B. analyzed data; M.S.P. and M.K. wrote the paper.

This work was supported by National Institutes of Health Grants R01MH101162 and T32GM007507. We thank Brian Knutson for assistance with task design and Rasmus Birn for help with data analysis.

The authors declare no competing financial interests.

Correspondence should be addressed to Michael Koenigs, Department of Psychiatry, University of Wisconsin-

Madison, 6001 Research Park Boulevard, Madison, Wisconsin 53719. E-mail: mrkoenigs@wisc.edu.

DOI:10.1523/JNEUROSCI.4236-15.2016

Copyright $\odot 2016$ the authors $\quad 0270-6474 / 16 / 365047-08 \$ 15.00 / 0$
}

making, and social behavior. Two central nodes of the reward circuit are the ventral striatum/nucleus accumbens and ventromedial prefrontal cortex (vmPFC). The ventral striatum has been particularly associated with the anticipation or prediction of reward, whereas the vmPFC has been linked to reward outcome and subjective value (Knutson et al., 2003; Grabenhorst and Rolls, 2011; Liu et al., 2011; Levy and Glimcher, 2012). Damage to the vmPFC in humans disrupts value-based decision-making and social function (Bechara et al., 1997; Camille et al., 2004, 2011; Koenigs and Tranel, 2007; Koenigs et al., 2007), and dysfunction in this circuit is observed across a broad range of psychopathology (Kalivas and Volkow, 2005; Tremblay et al., 2005; Epstein et al., 2006; Scheres et al., 2007; Harrison et al., 2009; Plichta et al., 2009; Waltz et al., 2009; Koob and Volkow, 2010; Scott-Van Zee- 
land et al., 2010; Figee et al., 2011; Jung et al., 2011; Dichter et al., 2012; Morris et al., 2012; Nielsen et al., 2012; Robinson et al., 2012).

Despite the importance of this brain circuit for mental health and adaptive decision-making, the neural interactions between the vmPFC and ventral striatum are not fully understood. Rodent studies have shown that the vmPFC has direct glutamatergic projections to the ventral striatum (Sesack et al., 1989; Voorn et al., 2004; Gabbott et al., 2005) and that inactivation of the vmPFC alters neuronal activity in the ventral striatum (Ghazizadeh et al., 2012). These studies indicate that the vmPFC may play a role in modulating ventral striatum activity. Human functional imaging studies have yielded additional correlational support for this idea; the vmPFC and ventral striatum exhibit strong functional connectivity at rest ( $\mathrm{Di}$ Martino et al., 2008; Cauda et al., 2011; Choi et al., 2012) and are often coactivated during reward processing tasks (Cauda et al., 2011). However, there is not yet evidence that the vmPFC actually modulates ventral striatum activity in humans. In other words, whereas animal studies have demonstrated that the vmPFC plays a causal role in modulating ventral striatum activity, there are no comparable data in humans to address whether the vmPFC may be critical for the reward-related response properties of ventral striatum.

In this study, we use fMRI in neurosurgical patients with focal vmPFC lesions to test the hypothesis that the vmPFC is necessary for enhancing ventral striatum responses to the anticipation of reward.

\section{Materials and Methods}

Participants. The target lesion group consisted of five adult neurosurgical patients ( $n=3$ males; $n=2$ females) with extensive bilateral parenchymal damage, primarily confined to the vmPFC, defined as the medial one-third of the orbital surface and the ventral one-third of the medial surface of the PFC bilaterally (Fig. 1). Each of the five patients underwent surgical resection of a large anterior cranial fossa meningioma via craniotomy. Initial clinical presentations included subtle or obvious personality changes over several months preceding surgery. On postsurgical MRI, although vasogenic edema mostly resolved, there were persistent $\mathrm{T}_{2}$-weighted signal changes consistent with gliosis and degeneration of white matter fibers in the vmPFC bilaterally. All experimental procedures were conducted $>3$ months after surgery, when the expected recovery was complete. At the time of testing (range of time elapsed since surgery, 32-75 months), all patients had focal, stable MRI signal changes and resection cavities and were free of dementia and substance abuse. Seventeen healthy adults ( $n=10$ males; $n=7$ females) with no history of brain injury, neurological or psychiatric illness, or current use of psychoactive medication were recruited as a normal comparison (NC) group. Demographic and neuropsychological data for the vmPFC and NC groups are summarized in Table 1.

fMRI task. To assess ventral striatum activity, we used an fMRI task involving the anticipation of monetary reward (Monetary Incentive Delay task), which has been used extensively to examine reward-related neural responses in healthy and patient populations (Knutson et al., 2008; Ströhle et al., 2008; Beck et al., 2009; Khemiri et al., 2012; Nielsen et al., 2012; Stoy et al., 2012; Gleichgerrcht and Young, 2013). Previous fMRI research with this task has reliably demonstrated ventral striatum
4321

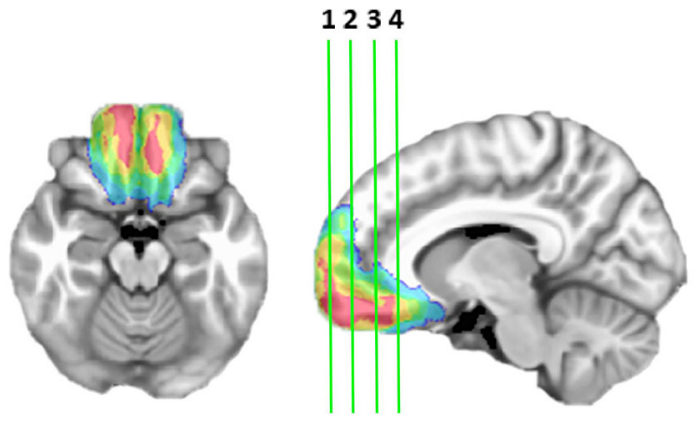

2

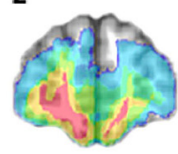

3
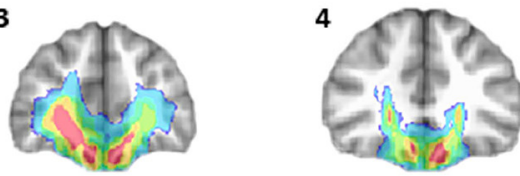

\# of patients with damage

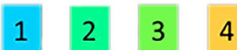

Figure 1. Lesion overlap of vmPFC-lesioned patients. Color indicates the number of overlapping lesions at each voxel. For axial and coronal views, the left side of the brain is displayed on the right.

activity in response to cues indicating the potential gain of money (Khemiri et al., 2012; Gleichgerrcht and Young, 2013). Hence, this task provides a well established fMRI measure of ventral striatum response to reward. Each trial consists of three periods. During the initial $2 \mathrm{~s}$ cue period, the subject views one of six different shapes (with circles indicating potential gains and squares indicating potential losses) displaying the amount of money that could be gained or lost on that trial $(+\$ 0.00$, $+\$ 1.00,+\$ 5.00,-\$ 0.00,-\$ 1.00,-\$ 5.00)$, followed by a $2 \mathrm{~s}$ fixation cross display (anticipation phase). During the following reaction-time task period (performance phase), the subject presses a button in response to a visual prompt (a solid white triangle) as quickly as possible. If the subject responds quickly enough while the prompt is displayed, the subject either gains money or avoids losing money on that trial. The third task period (outcome phase) indicates the monetary result based on the response (e.g., $+\$ 1.00$ for a successful response during a gain trial or $-\$ 5.00$ for an unsuccessful response during a loss trial) for $2 \mathrm{~s}$. The task difficulty for individual subjects was manipulated based on performance across the task, such that each subject successfully hit the target on $\sim 66 \%$ of the trials for each cue type. The entire task consisted of one functional run of $\sim 20 \mathrm{~min}$, consisting of 908 -s trials ( 15 trials for each of the six cue types) presented in pseudorandom order, followed by an intertrial interval of 2,4 , or $6 \mathrm{~s}$.

Before scanning, subjects were informed of all cue-outcome contingencies and completed a practice task consisting of 15 trials to ensure task comprehension and accurate reaction time calibration. Subjects completed the practice task twice outside the scanner and once inside the scanner during $\mathrm{T}_{1}$ acquisition, before the start of the full-length task. At the start of the scanning session, subjects were told that they would receive additional payment corresponding to their cumulative earnings on the full-length reward task.

After the scan, subjects were brought to a separate room and asked to rate their overall arousal and valence for each cue type using a scale ranging from 1 (arousal, "not at all aroused"; valence, "very negative") to 7 (arousal, "highly aroused"; valence, "very positive").

MRI data acquisition. All structural and functional MRI data were acquired using a 3.0 T GE Discovery MR750 scanner equipped with an eight-channel radio-frequency head coil array (GE Healthcare). Highresolution $\mathrm{T}_{1}$-weighted anatomical images were acquired using an inversion-recovery spoiled gradient recalled acquisition in steady state (spoiled gradient-recalled acquisition in a steady state) sequence (TR, 8.2 $\mathrm{ms}$; TE, $3.2 \mathrm{~ms} ; \alpha=12^{\circ}$; FOV, $256 \times 256 \mathrm{~mm}$; matrix, $256 \times 256$; in-plane resolution, $1 \times 1 \mathrm{~mm}^{2}$; slice thickness, $1 \mathrm{~mm}$; 1024 axial slices). 
Table 1. Subject characteristics

\begin{tabular}{|c|c|c|c|c|c|c|c|c|c|c|c|c|c|}
\hline & Age (years) & Sex & Edu & IQ & BIS total & BAS total & BASD & BASFS & BAS RR & Pos Aff & Neg Aff & BDI-II & STAI-T \\
\hline & & & & & & & & & & & & & \\
\hline & 6 & & $17.1(2.4)$ & & 18.9( & & & $11.4(1.9)$ & $16.1(2.0)$ & $39.9(7.2)$ & & & $29.6(5$. \\
\hline (vmPFC vs NC) & 0.39 & 0.86 & 0.44 & 0.13 & 0.11 & 0.82 & 0.75 & 0.96 & 0.96 & 0.72 & 0.62 & 0.22 & 0.34 \\
\hline
\end{tabular}

Means are presented with SDs in parentheses. Edu, Years of education; IQ, intelligence quotient estimated by the Wide Range Achievement Test 4, Blue Reading subtest (Wilkinson and Robertson, 2006); BIS/BAS, scores from the Behavioral Inhibition System/Behavioral Approach System, with subtests for drive (D), fun seeking (FS), and reward responsiveness (RR) (Carver and White, 1994); Pos/Neg Aff, scores from the Positive and Negative Affect Schedule (Watson et al., 1988), BDI-II, Beck Depression Inventory-II (Beck et al., 1996); STAl-T, trait version of the Spielberger State Trait Anxiety Inventory (Spielberger et al., 1983). A recently published study from our laboratory (Pujara et al., 2015) demonstrates abnormal value-based decision-making in the same sample of vmPFC-lesioned patients who participated in the current study.

To facilitate lesion segmentation, we collected a separate $\mathrm{T}_{2}$-weighted fluid-attenuated inversion recovery scan (FLAIR; TR, $8650 \mathrm{~ms}$; TE, 136 $\mathrm{ms} ; \alpha=0^{\circ}$; FOV, $220 \times 220 \mathrm{~mm}^{2}$; matrix, $512 \times 512$; in-plane resolution, $0.43 \times 0.43 \mathrm{~mm}^{2}$; slice thickness, $5 \mathrm{~mm}$; gap, $1 \mathrm{~mm}$; 25 axial slices).

Baseline resting cerebral blood flow (CBF) was estimated using a $3 \mathrm{D}$ fast spin echo spiral sequence with pseudocontinuous arterial spin labeling (pcASL; Dai et al., 2008; Xu et al., 2010; Okonkwo et al., 2014) and background suppression for quantitative perfusion measurements (TR, $4653 \mathrm{~ms}$; TE, $10.5 \mathrm{~ms}$; post-labeling delay, $1525 \mathrm{~ms}$; labeling duration, $1450 \mathrm{~ms}$; eight interleaved spiral arms with 512 samples at $62.5 \mathrm{kHz}$ bandwidth and 38.4-mm-thick slices; number of excitations, 3; scan duration, $4.5 \mathrm{~min})$.

Whole-brain functional scans were acquired using a $\mathrm{T}_{2}{ }^{*}$-weighted gradient-echo echoplanar imaging (EPI) sequence (TR, $2000 \mathrm{~ms}$; TE, 22 $\mathrm{ms} ; \alpha=79^{\circ}$; FOV, $224 \times 224 \mathrm{~mm}^{2}$; matrix, $64 \times 64$; in-plane resolution, $3.5 \times 3.5 \mathrm{~mm}^{2}$; slice thickness, $3 \mathrm{~mm}$; gap, $0.5 \mathrm{~mm}$; 38 interleaved axial oblique slices). Field maps were acquired using two separate acquisitions (TR, $600 \mathrm{~ms} ; \mathrm{TE}_{1}, 7 \mathrm{~ms}$; $\mathrm{TE}_{2}, 10 \mathrm{~ms} ; \alpha=60^{\circ}$; FOV, $240 \times 240 \mathrm{~mm}^{2}$; matrix, $256 \times 128$; slice thickness, $4 \mathrm{~mm}$; 33 axial oblique slices). Restingstate functional images were collected while subjects lay still and awake, passively viewing a fixation cross for $5 \mathrm{~min}$. Scans were acquired in the following order: pcASL, field map, rest, $\mathrm{T}_{1}$, task, $\mathrm{T}_{2}$ FLAIR.

Lesion segmentation and image normalization. Individual vmPFC lesions were visually identified and manually segmented on the $\mathrm{T}_{1^{-}}$ weighted images. Lesion boundaries were drawn to include areas with gross tissue damage or abnormal signal characteristics on $\mathrm{T}_{1}$ or $\mathrm{T}_{2}$ FLAIR images. $\mathrm{T}_{1}$-weighted images were skull stripped, rigidly coregistered with a functional volume from each subject, and then diffeomorphically aligned to the Montreal Neurological Institute (MNI) coordinate system using a Symmetric Normalization algorithm (Avants and Gee, 2004) with constrained cost-function masking to prevent warping of tissue within the lesion mask (Brett et al., 2001). We created the lesion overlap map (Fig. 1) by computing the sum of aligned binary lesion masks for all five vmPFC patients. Alignment parameters computed during this step were used in the subsequent normalization of all anatomical and functional data to MNI space.

fMRI task preprocessing and analysis. Data analysis was conducted using AFNI (Automated Functional Neuro-Imaging; Cox, 1996) and FSL (Functional MRI of the Brain Software Library; http://www.fmrib.ox.ac. $\mathrm{uk} / \mathrm{fs} \mathrm{l}$ ) software. The task run was slice time corrected, field map corrected (Jezzard and Clare, 1999), motion corrected, smoothed with a 4 mm full-width half-maximum (FWHM) Gaussian kernel, scaled to percentage signal change (PSC), aligned to MNI space, and resampled to 3 $\mathrm{mm}^{3}$ isotropic resolution. Anticipatory activity was modeled using a duration-modulated boxcar regressor, beginning at cue onset and spanning the $4 \mathrm{~s}$ anticipation phase (cue and fixation cross) before the presentation of the target. All six cue regressors were included in a general linear model (GLM) with six additional regressors for each outcome (gains of $\$ 0, \$ 1$, or $\$ 5$; losses of $\$ 0, \$ 1$, or $\$ 5$ ). The GLM also included several regressors of no interest: six motion covariates from rigid-body alignment (Johnstone et al., 2006) and a fourth-order polynomial to model baseline and slow signal drift. To avoid potential confounds introduced by subject motion, volumes in which $>10 \%$ of voxels were time series outliers were censored before conducting the GLM.

One vmPFC-lesioned patient was rescanned because of input device malfunction during the first scan. Three NC subjects ( $n=1$ male; $n=2$ females) were excluded from task-based analyses because of excessive head motion (>2 mm; Power et al., 2012), for a total sample size of $14 \mathrm{NC}$ subjects ( $n=9$ males; $n=5$ females). There were no group differences in the percentage of censored volumes $(W=60.5, p=0.84$ ) or in mean framewise displacement (NC, $0.06 \pm 0.02 \mathrm{~mm}$; vmPFC, $0.07 \pm 0.03 \mathrm{~mm}$; $W=134.0, p=0.31$ ). Resulting whole-brain maps of voxelwise $\beta$ values for sustained BOLD responses, in MNI space at $3 \mathrm{~mm}^{3}$ isotropic resolution, were used for second-level analyses.

To identify brain regions responsive to the anticipation of monetary gain, we first performed a whole-brain, two-tailed paired-sample $t$ test between responses to gain cues (collapsed across magnitude) and the neutral gain cue $(+\$ 0)$ using only the $14 \mathrm{NC}$ subjects (Chen et al., 2013). All statistical maps were familywise error (FWE) corrected for multiple comparisons across the whole brain at the cluster level $\left(p_{\mathrm{FWE}}<0.05\right)$, using a height threshold of $p<0.001$ (Forman et al., 1995; Carp, 2012). A corrected $p_{\text {FWE }}<0.05$ was achieved using a cluster extent threshold of 20 voxels $\left(540 \mathrm{~mm}^{3}\right)$, calculated using Monte Carlo simulations with 3dClustSim (December 2015 version) in AFNI.

Because of the small sample size of patients with vmPFC lesions, we used nonparametric Mann-Whitney $U$ tests to evaluate our main a priori hypothesis regarding activity of the ventral striatum and behavioral differences between groups (percentage of hits by condition, postscan valence and arousal ratings by condition, target duration by condition, and cumulative money earned from the task). Specifically, we focused our between-group analyses on PSC estimates extracted from functionally derived right and left ventral striatum ROIs (ventral striatum clusters from the gain $>$ neutral contrast in the $\mathrm{NC}$ group). We used functional ROIs to ensure that group comparisons were conducted within functionally relevant regions within the ventral striatum (i.e., regions that responded strongly in anticipation of potential gains in healthy subjects; Poldrack, 2007). However, to confirm that group comparisons within functionally derived ventral striatum ROIs reflected differences in ventral striatum activity, we conducted additional between-group tests using values extracted from ROIs in the right and left ventral striatum (number of voxels in masks, $n_{\text {right }}=99, n_{\text {left }}=107$ ), created from subregions in a striatal parcellation atlas derived from functional connectivity to 17 distinct cortical networks in 1000 healthy adults (Choi et al., 2012). The chosen subregions, which correspond to regions 10 and 17 in the 17network parcellation map (available at http://www.freesurfer.net/fswiki/ StriatumParcellation_Choi 2012), demonstrated functional connectivity in the healthy adults to cortical areas corresponding to the region of damage in our vmPFC-lesioned patient sample.

To test the specificity of observed effects to the ventral striatum, we conducted follow-up analyses on PSC values extracted from the remaining functionally derived regions outside the ventral striatum. All tests were considered significant at $p<0.05$.

Volumetric analysis. The averaged $\mathrm{T}_{1}$-weighted images were processed using FreeSurfer (Forman et al., 1995; Fischl, 2012). The FreeSurfer tissue segmentation includes volume measurements (in cubic millimeters) for four striatal subregions in each hemisphere. We used nonparametric Mann-Whitney $U$ tests to calculate group differences in volumes of the following striatal subregions: left and right putamen, left and right caudate, left and right accumbens, and left and right pallidum. We also calculated group differences in volumes of two additional subcortical limbic structures - the amygdala and hippocampus - to further examine specificity. All regional volumes were corrected for estimated intracranial volume (Sanfilipo et al., 2004).

Cerebral perfusion analysis. Quantitative CBF images from pcASL were rigidly coregistered with a $\mathrm{T}_{2}{ }^{*}$-weighted EPI volume from the task scan and normalized to MNI space. Normalized CBF volumes were scaled to 
Table 2. Behavioral data

\begin{tabular}{|c|c|c|c|c|c|c|}
\hline & \multirow[b]{2}{*}{ Gain/loss } & \multicolumn{2}{|l|}{ vmPFC } & \multicolumn{2}{|l|}{ NC } & \multirow[b]{2}{*}{$p$} \\
\hline & & Mean & SD & Mean & SD & \\
\hline \multirow[t]{6}{*}{$\%$ Hits } & $-\$ 0$ & 65.3 & 5.6 & 62.1 & 5.7 & 0.34 \\
\hline & $-\$ 1$ & 53.3 & 19.4 & 59.0 & 10.5 & 0.92 \\
\hline & $-\$ 5$ & 68.0 & 7.3 & 65.6 & 7.1 & 0.78 \\
\hline & $+\$ 0$ & 62.3 & 7.6 & 61.5 & 10.2 & 0.99 \\
\hline & $+\$ 1$ & 66.7 & 4.7 & 57.9 & 12.3 & 0.21 \\
\hline & $+\$ 5$ & 64.0 & 3.7 & 60.5 & 11.0 & 0.70 \\
\hline \multirow[t]{6}{*}{ Arousal ratings } & $-\$ 0$ & 2.6 & 1.5 & 2.8 & 1.4 & 0.85 \\
\hline & $-\$ 1$ & 2.8 & 1.6 & 3.3 & 1.5 & 0.63 \\
\hline & $-\$ 5$ & 3.2 & 2.2 & 4.5 & 2.4 & 0.29 \\
\hline & $+\$ 0$ & 3.0 & 1.6 & 2.9 & 1.3 & 0.92 \\
\hline & $+\$ 1$ & 4.4 & 1.3 & 4.4 & 1.3 & 0.85 \\
\hline & $+\$ 5$ & 6.0 & 0.7 & 6.0 & 1.2 & 0.78 \\
\hline \multirow[t]{6}{*}{ Valence ratings } & $-\$ 0$ & 3.4 & 1.3 & 4.2 & 0.9 & 0.34 \\
\hline & $-\$ 1$ & 3.8 & 0.4 & 3.9 & 0.8 & 0.99 \\
\hline & $-\$ 5$ & 3.6 & 2.4 & 2.7 & 1.5 & 0.50 \\
\hline & $+\$ 0$ & 3.6 & 1.1 & 4.2 & 0.4 & 0.39 \\
\hline & $+\$ 1$ & 4.6 & 1.1 & 4.9 & 0.6 & 0.63 \\
\hline & $+\$ 5$ & 6.0 & 1.0 & 5.8 & 1.5 & 0.99 \\
\hline \multirow[t]{6}{*}{ Target duration (ms) } & $-\$ 0$ & 367 & 61 & 352 & 77 & 0.69 \\
\hline & $-\$ 1$ & 345 & 77 & 333 & 83 & 0.56 \\
\hline & $-\$ 5$ & 350 & 85 & 328 & 71 & 0.89 \\
\hline & $+\$ 0$ & 352 & 71 & 354 & 56 & 0.96 \\
\hline & $+\$ 1$ & 378 & 67 & 336 & 92 & 0.19 \\
\hline & $+\$ 5$ & 334 & 82 & 322 & 84 & 0.82 \\
\hline Payment & & $\$ 27.00$ & $\$ 8.06$ & $\$ 22.15$ & $\$ 12.49$ & 0.50 \\
\hline
\end{tabular}

Note that, because of a computer malfunction, the behavioral data for one NC subject was not available.

whole-brain CBF (after masking out the lesion in vmPFC patients) and smoothed with a $6 \mathrm{~mm}$ FWHM Gaussian kernel. To rule out differences in baseline cerebral perfusion, we examined group differences in mean whole-brain CBF and differences in scaled CBF for all functionally defined ROIs using nonparametric Mann-Whitney $U$ tests.

\section{Results}

Behavioral data

Groups did not significantly differ with respect to task performance (percentage of hits by condition, postscan valence and arousal ratings by condition, target duration by condition, and cumulative money earned from the task; all comparisons $p>$ 0.19 ). These behavioral data for the vmPFC and NC groups are summarized in Table 2.

\section{fMRI task data}

Relative to the neutral cue, gain anticipation elicited robust bilateral striatum activity in the NC subjects (Fig. 2; Table 3). To examine group differences in striatum activity, we extracted PSC estimates from these functionally derived right and left striatum ROIs. In support of our main hypothesis, patients with vmPFC lesions exhibited significantly less activity in the right striatum $(W=64.0, p=0.005)$ and left striatum $(W=59.0, p=0.03)$ during gain anticipation than did NC subjects (Fig. 2). This effect was present for the high gain $\$ 5$ cue $>\$ 0$ cue contrast (right striatum, $W=64.0, p=0.005$; left striatum, $W=60.0, p=0.02$ ) but not the low gain $\$ 1$ cue $>\$ 0$ cue contrast (right striatum, $W=54.0, p=0.09$; left striatum, $W=47.0, p=0.30$ ). Consistent with the results based on functionally derived ROIs, we observed a significant group difference for the $\$ 5$ cue $>\$ 0$ cue contrast for the a priori right ventral striatum ROI $(W=28.0, p=0.04)$ and a trend-level group difference for the $\$ 5$ cue $>\$ 0$ cue contrast for the a priori left ventral striatum ROI ( $W=30.0, p=0.07$ ).

To test the anatomical specificity of group differences in activity related to gain anticipation (Table 3), we conducted follow-up analyses in the three remaining functionally derived
ROIs from the gain $>$ neutral cue contrast [e.g., left paracentral lobule/medial frontal gyrus (MFG), left inferior parietal lobule (IPL), and right caudate] and found similar group differences (left MFG, $W=68.0, p=0.0007$; left IPL, $W=64.0, p=0.005$; right caudate, $W=63.0, p=0.007)$.

To ensure that the hypothesized group differences in the functionally defined striatum regions were not attributable to baseline differences in perfusion after vmPFC damage, we estimated CBF using pcASL before the functional scan in all subjects. There were no significant differences between groups for whole-brain CBF ( $W=26, p=0.44$ ) or for either of the functionally defined striatum ROIs (right, $W=50.0, p=0.19$; left, $W=41.0, p=0.62$ ).

\section{Volumetric data}

Compared with the NC group, the vmPFC group had significantly smaller volumes of the accumbens subregion of the left ventral striatum $(W=57.0, p=0.04)$ and a trend-level difference for the right accumbens subregion of the ventral striatum ( $W=54, p=0.09$; Fig. 3 ). There were no significant group differences for any other region of the striatum (right putamen, $W=33.0, p=0.49$; left putamen, $W=38.0, p=0.76$; right caudate, $W=29.0, p=0.32$; left caudate, $W=28.0, p=0.28$; right pallidum, $W=34.0, p=0.54$; left pallidum, $W=46.0, p=0.82$ ), amygdala (right, $W=44.0, p=0.93$; left, $W=35.0, p=0.59$ ), or hippocampus (right, $W=52, p=0.49$; left, $W=45.0, p=0.88$; Table 4).

\section{Discussion}

Through a novel application of $\mathrm{AMRI}$ in patients with bilateral vmPFC damage, we have demonstrated a critical role for the vmPFC in modulating the reward-related activity and structure of the ventral striatum. Specifically, we found that vmPFC lesions were associated with decreased ventral striatal activity during the anticipation of reward and decreased volumes of the accumbens subregion of the ventral striatum. These results are germane to neural circuitry models of reward processing and mental illness.

First, with respect to neural circuitry models of reward processing, the study results fill an empirical gap between previous animal and human research findings. Human fMRI studies have consistently shown that the vmPFC and ventral striatum exhibit coincident activity (Di Martino et al., 2008; Cauda et al., 2011; Choi et al., 2012). However, a fundamental limitation of this correlational approach is that it does not distinguish between cause and consequence within the network of observed activity. In other words, is the observed coactivation of the vmPFC and ventral striatum during reward processing in these studies attributable to vmPFC activity modulating ventral striatum activity or vice versa? Or are activity changes in these areas just parallel, coincidental downstream effects triggered by activity elsewhere in the brain? Animal research suggests a causal effect of vmPFC activity on ventral striatum activity. Rodent studies have shown that the vmPFC has direct glutamatergic projections to the ventral striatum (Sesack et al., 1989; Voorn et al., 2004; Gabbott et al., 2005) and that inactivation of the vmPFC alters neuronal activity in the ventral striatum (Ghazizadeh et al., 2012). Lesioning or inactivating both the vmPFC and ventral striatum/accumbens disrupts behavioral responding during reward learning and reaction time tasks, indicating that adaptive decision-making depends on concurrent activation of both regions (Christakou et al., 2004; Peters et al., 2008; Bossert et al., 2012; St Onge et al., 2012; Richard and Berridge, 2013; Smith and Graybiel, 2013; Feja and Koch, 2015). The present study yields the first human evidence suggesting that the vmPFC does in fact have a causal influence on modulating ventral striatum activity, in that deprivation of vmPFC 
a

Gain > Neutral Activity

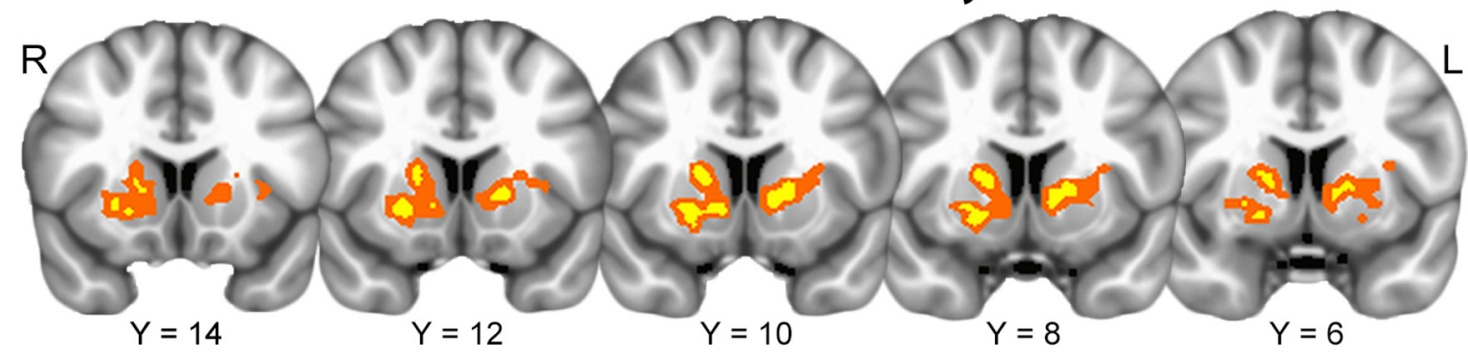

\begin{tabular}{|l|l|}
\hline$p<0.005$ & $p<0.001$ \\
\hline
\end{tabular}

b

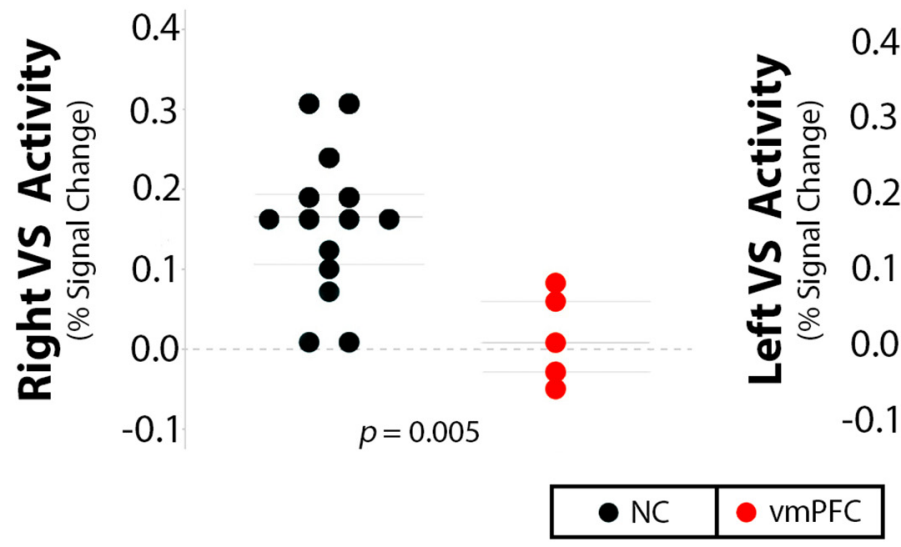

Figure 2. a, Striatal regions with greater activation to gain, relative to neutral, cues in $14 \mathrm{NC}$ subjects. Significant striatum clusters from the gain $>$ neutral contrast at $p<0.005$ uncorrected in orange and $p<0.001$ in yellow $\left(p_{\text {FWE }}<0.05\right.$ ) for display. Slice coordinates (in millimeters) are presented in MNI template space. $\boldsymbol{b}$, Plots depict the distribution of individual PSC values for vmPFC-lesioned patients (red circles) and NC subjects (black circles) in response to gain $(+5,+1)$ minus neutral $(+0)$ cues within each striatum cluster at $p<0.001$ uncorrected, $p_{\text {FWE }}<0.05$. Light gray horizontal lines on the plots represent the mean and the first and third quartiles of PSC values for each group.

Table 3. Brain regions sensitive to anticipatory cues in the NC group

\begin{tabular}{|c|c|c|c|c|c|c|c|}
\hline \multirow[b]{2}{*}{ Contrast } & \multirow[b]{2}{*}{ Structure } & \multicolumn{2}{|c|}{ Cluster } & \multicolumn{4}{|c|}{ Peak voxel } \\
\hline & & Size & $p_{\text {FWE }}$ & $T$ & $x$ & $y$ & $z$ \\
\hline \multirow[t]{6}{*}{ Gain $>$ neutral } & L Striatum & 26 & $<0.001$ & 5.40 & +15.5 & -9.5 & +3.5 \\
\hline & R Striatum \#1 & 34 & $<0.001$ & 5.92 & -20.5 & -9.5 & -5.5 \\
\hline & R Striatum \#2 & 29 & $<0.001$ & 6.76 & -17.5 & -6.5 & +9.5 \\
\hline & L MFG & 218 & $<0.001$ & 7.21 & +6.5 & +20.5 & +66.5 \\
\hline & LIPL & 192 & $<0.001$ & 7.31 & +27.5 & +44.5 & +39.5 \\
\hline & R Caudate & 29 & $<0.001$ & 6.76 & -17.5 & -6.5 & +9.5 \\
\hline Loss $>$ neutral & - & - & - & - & - & - & - \\
\hline
\end{tabular}

Cluster size in number of voxels $\left(3 \times 3 \times 3 \mathrm{~mm}^{3}\right)$. Corrected $p$ thresholds indicate minimum FWE-corrected $p$ value for each cluster. Peak voxel coordinates (millimeters) are presented in MNI space. BA, Brodmann area; L, left; R, right.

input (via focal lesion) results in reduced ventral striatum activity during the anticipation of reward. This finding accords with human lesion studies that demonstrate impairments in value-based decision-making after vmPFC damage (Zald and Andreotti, 2010; Fellows, 2011). In the context of these behavioral effects, our fMRI data suggest a critical role for the vmPFC in modulating anticipatory ventral striatal responses to potential rewards.

The present findings may also help inform neural circuitry models of mental illness. Clinical neuroimaging studies have consistently identified abnormalities in reward circuit function and decisionmaking across a range of psychiatric disorders, including major depression (Tremblay et al., 2005; Epstein et al., 2006; Robinson et al., 2012), schizophrenia (Waltz et al., 2009; Morris et al., 2012; Nielsen et al., 2012), substance use disorders (Kalivas and Volkow, 2005; Koob and Volkow, 2010), attention-deficit hyperactivity disorder (Scheres et al., 2007; Plichta et al., 2009), obsessive-compulsive dis- order (Harrison et al., 2009; Figee et al., 2011; Jung et al., 2011), and autism (Scott-Van Zeeland et al., 2010; Dichter et al., 2012). Clarifying the functional architecture of this circuit is thus an important step in advancing the neuropathophysiological understanding of mental illness. The present results suggest that vmPFC dysfunction may contribute to psychopathology by disrupting ventral striatal activity.

In addition to the diminished reward-related activity in the ventral striatum, we also observed reduced ventral striatum volumes in the vmPFC-lesioned patients. Importantly, this volume reduction was specific to the accumbens subregion of the striatum; the volumes of all other striatal subregions (caudate, putamen, pallidum) and other limbic subregions (amygdala, hippocampus) did not significantly differ between groups. The specificity of this finding mirrors known anatomical connections between the vmPFC and striatum, which share a particularly high density of reciprocal axonal connections (Haber and Knutson, 2010; Rigoard et al., 2011). It is possible that the ventral striatum volume reduction among vmPFC-lesioned patients is attributable to diminished input from vmPFC and/or retrograde degeneration from damaged axonal connections. Regardless, the complementary fMRI and volumetric findings underscore the tight link between structure and function in this brain circuit.

Although our study hypothesis focused on the ventral striatum, we also observed activity related to gain anticipation in the lateral parietal cortex. This finding accords with electrophysiological studies of nonhuman primates, which have consistently demonstrated reward-related neuronal activity in the lateral parietal cortex during decision-making and reinforcement learning (Platt and Glimcher, 


\section{a \\ Accumbens Area Volume}

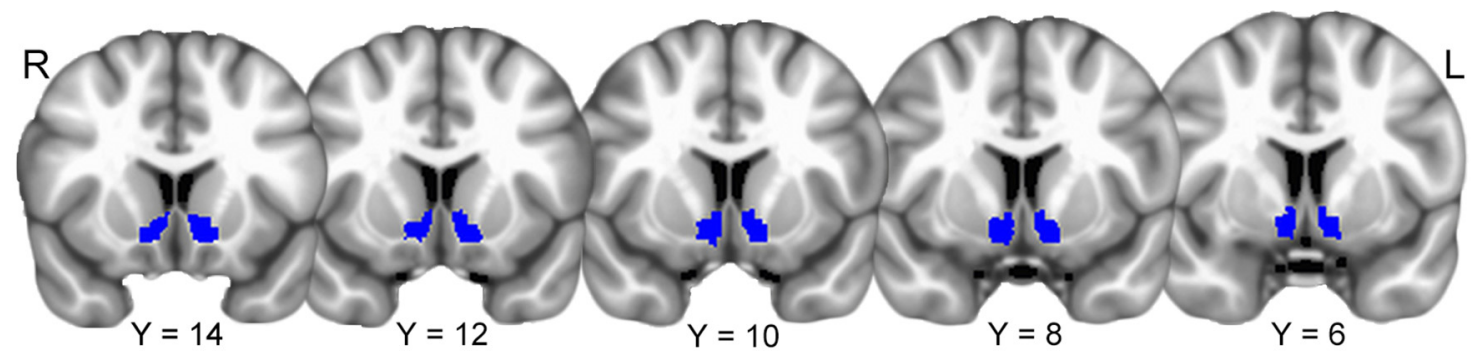

b
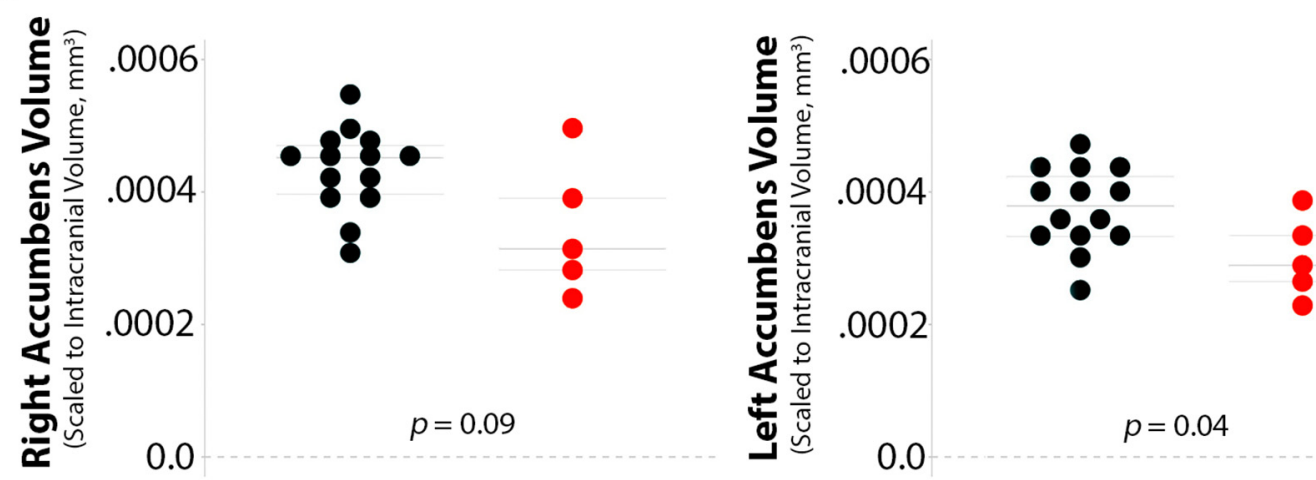

$p=0.04$

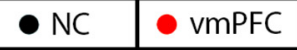

Figure 3. $\boldsymbol{a}$, Accumbens area (ventral striatum) subregions of a representative subject. $\boldsymbol{b}$, Plots depict the distribution of individual volume values (in cubic millimeters) for vmPFC-lesioned patients (red circles) and NC subjects (black circles) for each accumbens area region of interest, scaled to total estimated intracranial volume. Light gray horizontal lines on the plots represent the mean and the first and third quartiles of volume values for each group.

Table 4. Volumetric data

\begin{tabular}{|c|c|c|c|c|c|c|}
\hline \multirow[b]{2}{*}{ Region } & \multicolumn{2}{|l|}{ NC } & \multicolumn{2}{|l|}{ vmPFC } & \multirow[b]{2}{*}{ W } & \multirow[b]{2}{*}{$p$} \\
\hline & Mean & SD & Mean & SD & & \\
\hline \multicolumn{7}{|l|}{ Striatum } \\
\hline LNAC & 568.8 & 126.2 & 481.14 & 129.8 & 57.0 & 0.04 \\
\hline RNAC & 658.5 & 121.4 & 549.9 & 184.1 & 54.0 & 0.09 \\
\hline L caudate & 3397.1 & 573.4 & 3773.8 & 381.4 & 28.0 & 0.28 \\
\hline R caudate & 3645.2 & 679.7 & 4059.6 & 641.7 & 29.0 & 0.32 \\
\hline L putamen & 5248.1 & 724.0 & 5557.4 & 620.6 & 38.0 & 0.76 \\
\hline R putamen & 5052.2 & 651.1 & 5427.2 & 502.9 & 33.0 & 0.49 \\
\hline L pallidum & 1319.2 & 182.3 & 1407.9 & 260.6 & 46.0 & 0.82 \\
\hline Rpallidum & 1447.5 & 257.6 & 1527.9 & 190.0 & 34.0 & 0.54 \\
\hline \multicolumn{7}{|l|}{ Amygdala } \\
\hline L amygdala & 1527.7 & 260.2 & 1634.6 & 221.4 & 35.0 & 0.59 \\
\hline Ramygdala & 1680.1 & 272.0 & 1753.2 & 417.5 & 44.0 & 0.93 \\
\hline \multicolumn{7}{|l|}{ Hippocampus } \\
\hline L hippocampus & 3943.8 & 296.9 & 4199.2 & 486.8 & 45.0 & 0.88 \\
\hline R hippocampus & 4138.6 & 324.3 & 4314.5 & 453.1 & 52.0 & 0.49 \\
\hline Total estimated ICV & 1507627.1 & 146862.7 & 1587332.61 & 145817.2 & 23.0 & 0.30 \\
\hline
\end{tabular}

Significant group differences are in bold. L, Left; $R$, right; NAc, nucleus accumbens; ICV, intracranial volume.

1999; Dorris and Glimcher, 2004; Sugrue et al., 2004; Peck et al., 2009; Seo et al., 2009; Louie and Glimcher, 2010). Our finding that reward-related activity in the parietal cortex was significantly reduced in the vmPFC-lesioned patients suggests that vmPFC damage may attenuate reward-related signals outside the striatum.

One limitation of the present study is the inability to determine whether the vmPFC was engaged in response to reward cues in normal subjects. Unfortunately, the area of vmPFC damage in our patient sample corresponds almost exactly to the area of maximal fMRI signal dropout attributable to magnetic field inhomogeneities. In addition, the lesions almost certainly involved damage to white matter pathways in and around the vmPFC.
Hence, we are unable to determine whether vmPFC damage disrupted local processing during the task, or perhaps impaired communication between the striatum and other cortical areas via damage to underlying white matter. To account for the absence of a lesion control group, we assessed baseline cerebral perfusion. Because ASL data indicated no gross alterations of perfusion in the vmPFC patients (either globally or in ventral striatum), the observed group differences in task activation cannot be readily explained by group differences in cerebral perfusion.

Another limitation of this study is that the Monetary Incentive Delay (MID) fMRI paradigm does not provide a sensitive behavioral measure of reward processing. To more conclusively determine the behavioral relevance of the observed abnormalities in ventral striatum structure and function, future studies could examine the link between striatal neurobiology and established behavioral measures of reward learning or value-based decisionmaking. In addition, it will be important to determine whether vmPFC damage is associated with less improvement in behavioral performance based on incentives relative to neurologically healthy subjects. One early study reported a "small but reliable tendency" for reaction time decreasing with higher reward magnitude on a task of 250 rewarded trials (Stillings et al., 1968). Another study reported an effect of reward magnitude on reaction time on a task that included a total of 300 trials (Park et al., 2012). Our MID task only included 30 rewarded trials, because it was tailored specifically for fMRI data collection to address the hypothesis regarding ventral striatum activation. There are a few possible ways to assess behavioral differences between groups in future studies. One would be to use a longer version of the MID task outside of the scanner with a greater number of rewarded trials. Another would be to use a delay discounting task, which 
has been included as a behavioral test outside the scanner to complement the MID task in the scanner (Luo et al., 2009; Benningfield et al., 2014). A recent study examined incentivization by reward in vmPFC-lesioned patients using a speeded saccade task with an auditory incentive cue (Manohar and Husain, 2016). Consistent with our fMRI findings, vmPFC damage resulted in reduced saccadic velocity and autonomic pupil responses for rewards.

One feature of this study that warrants consideration is the limited sample size of vmPFC-lesioned patients $(n=5)$. For this study, we used extremely stringent selection criteria for our target group; lesions had to involve substantial portions of vmPFC bilaterally but could not extend significantly outside vmPFC. Furthermore, because the study involved fMRI, we could not include patients with metallic implants, such as aneurysm clips. To meet these criteria, we selected a group of patients who had all undergone surgical resection of large orbital meningiomas. So, although our sample size may be small by conventional vmPFC-lesioned patient standards (which typically feature $5-12 \mathrm{vmPFC}$-lesioned patients), it is unique with respect to the homogeneity of etiology, uniformity, and selectivity of bilateral vmPFC lesions and compatibility with fMRI.

In summary, these findings indicate a role for the vmPFC in contributing to reward-related activity of the ventral striatum. Our results offer new insight into the functional and structural interactions between the vmPFC and ventral striatum, two key components of the brain circuitry underlying human affective function and decision-making.

\section{References}

Avants B, Gee JC (2004) Geodesic estimation for large deformation anatomical shape averaging and interpolation. Neuroimage 23 [Suppl 1]: S139-S150. CrossRef Medline

Bechara A, Damasio H, Tranel D, Damasio AR (1997) Deciding advantageously before knowing the advantageous strategy. Science 275:12931295. CrossRef Medline

Beck AT, Steer RA, Brown GK (1996) Manual for the Beck Depression Inventory-II. San Antonio, TX: Psychological Corporation.

Beck A, Schlagenhauf F, Wüstenberg T, Hein J, Kienast T, Kahnt T, Schmack K, Hägele C, Knutson B, Heinz A, Wrase J (2009) Ventral striatal activation during reward anticipation correlates with impulsivity in alcoholics. Biol Psychiatry 66:734-742. CrossRef Medline

Benningfield MM, Blackford JU, Ellsworth ME, Samanez-Larkin GR, Martin PR, Cowan RL, Zald DH (2014) Caudate responses to reward anticipation associated with delay discounting behavior in healthy youth. Dev Cogn Neurosci 7:43-52. CrossRef Medline

Bossert JM, Stern AL, Theberge FR, Marchant NJ, Wang HL, Morales M, Shaham Y (2012) Role of projections from ventral medial prefrontal cortex to nucleus accumbens shell in context-induced reinstatement of heroin seeking. J Neurosci 32:4982-4991. CrossRef Medline

Brett M, Leff AP, Rorden C, Ashburner J (2001) Spatial normalization of brain images with focal lesions using cost function masking. Neuroimage 14:486-500. CrossRef Medline

Camille N, Coricelli G, Sallet J, Pradat-Diehl P, Duhamel JR, Sirigu A (2004) The involvement of the orbitofrontal cortex in the experience of regret. Science 304:1167-1170. CrossRef Medline

Camille N, Griffiths CA, Vo K, Fellows LK, Kable JW (2011) Ventromedial frontal lobe damage disrupts value maximization in humans. J Neurosci 31:7527-7532. CrossRef Medline

Carp J (2012) The secret lives of experiments: methods reporting in the fMRI literature. Neuroimage 63:289-300. CrossRef Medline

Carver CS, White TL (1994) Behavioral inhibition, behavioral activation, and affective responses to impending reward and punishment: the BIS/ BAS Scales. J Pers Soc Psychol 67:319-333. CrossRef

Cauda F, Cavanna AE, D'agata F, Sacco K, Duca S, Geminiani GC (2011) Functional connectivity and coactivation of the nucleus accumbens: a combined functional connectivity and structure-based meta-analysis. J Cogn Neurosci 23:2864-2877. CrossRef Medline

Chen G, Saad ZS, Britton JC, Pine DS, Cox RW (2013) Linear mixed-effects modeling approach to FMRI group analysis. Neuroimage 73:176-190. CrossRef Medline

Choi EY, Yeo BT, Buckner RL (2012) The organization of the human striatum estimated by intrinsic functional connectivity. J Neurophysiol 108: 2242-2263. CrossRef Medline

Christakou A, Robbins TW, Everitt BJ (2004) Prefrontal cortical-ventral striatal interactions involved in affective modulation of attentional performance: implications for corticostriatal circuit function. J Neurosci 24: 773-780. CrossRef Medline

Cox RW (1996) AFNI: software for analysis and visualization of functional magnetic resonance neuroimages. Comput Biomed Res 29:162-173. CrossRef Medline

Dai W, Garcia D, de Bazelaire C, Alsop DC (2008) Continuous flow-driven inversion for arterial spin labeling using pulsed radio frequency and gradient fields. Magn Reson Med 60:1488-1497. CrossRef Medline

Dichter GS, Felder JN, Green SR, Rittenberg AM, Sasson NJ, Bodfish JW (2012) Reward circuitry function in autism spectrum disorders. Soc Cogn Affect Neurosci 7:160-172. CrossRef Medline

Di Martino A, Scheres A, Margulies DS, Kelly AM, Uddin LQ, Shehzad Z, Biswal B, Walters JR, Castellanos FX, Milham MP (2008) Functional connectivity of human striatum: a resting state FMRI study. Cereb Cortex 18:2735-2747. CrossRef Medline

Dorris MC, Glimcher PW (2004) Activity in posterior parietal cortex is correlated with the relative subjective desirability of action. Neuron 44:365378. CrossRef Medline

Epstein J, Pan H, Kocsis JH, Yang Y, Butler T, Chusid J, Hochberg H, Murrough J, Strohmayer E, Stern E, Silbersweig DA (2006) Lack of ventral striatal response to positive stimuli in depressed versus normal subjects. Am J Psychiatry 163:1784-1790. CrossRef Medline

Feja M, Koch M (2015) Frontostriatal systems comprising connections between ventral medial prefrontal cortex and nucleus accumbens subregions differentially regulate motor impulse control in rats. Psychopharmacology (Berl) 232:12911302. CrossRef Medline

Fellows LK (2011) Orbitofrontal contributions to value-based decision making: evidence from humans with frontal lobe damage. Ann N Y Acad Sci 1239:51-58. CrossRef Medline

Figee M, Vink M, de Geus F, Vulink N, Veltman DJ, Westenberg H, Denys D (2011) Dysfunctional reward circuitry in obsessive-compulsive disorder. Biol Psychiatry 69:867-874. CrossRef Medline

Fischl B (2012) FreeSurfer. Neuroimage 62:774-781. CrossRef Medline

Forman SD, Cohen JD, Fitzgerald M, Eddy WF, Mintun MA, Noll DC (1995) Improved assessment of significant activation in functional magnetic resonance imaging (fMRI): use of a cluster-size threshold. Magn Reson Med 33:636-647. CrossRef Medline

Gabbott PL, Warner TA, Jays PR, Salway P, Busby SJ (2005) Prefrontal cortex in the rat: projections to subcortical autonomic, motor, and limbic centers. J Comp Neurol 492:145-177. CrossRef Medline

Ghazizadeh A, Ambroggi F, Odean N, Fields HL (2012) Prefrontal cortex mediates extinction of responding by two distinct neural mechanisms in accumbens shell. J Neurosci 32:726-737. CrossRef Medline

Gleichgerrcht E, Young L (2013) Low levels of empathic concern predict utilitarian moral judgment. PLoS One 8:e60418. CrossRef Medline

Grabenhorst F, Rolls ET (2011) Value, pleasure and choice in the ventral prefrontal cortex. Trends Cogn Sci 15:56-67. CrossRef Medline

Haber SN, Knutson B (2010) The reward circuit: linking primate anatomy and human imaging. Neuropsychopharmacology 35:4-26. CrossRef Medline

Harrison BJ, Soriano-Mas C, Pujol J, OrtizH, Lóez-Solà M, Hernández-Ribas R, Deus J, Alonso P, Yücel M, Pantelis C, Menchon JM, Cardoner N (2009) Altered corticostriatal functional connectivity in obsessive-compulsive disorder. Arch Gen Psychiatry 66:1189-1200. CrossRef Medline

Jezzard P, Clare S (1999) Sources of distortion in functional MRI data. Hum Brain Mapp 8:80-85. CrossRef Medline

Johnstone T, Ores Walsh KS, Greischar LL, Alexander AL, Fox AS, Davidson RJ, Oakes TR (2006) Motion correction and the use of motion covariates in multiple-subject fMRI analysis. Hum Brain Mapp 27:779-788. CrossRef Medline

Jung WH, Kang DH, Han JY, Jang JH, Gu BM, Choi JS, Jung MH, Choi CH, Kwon JS (2011) Aberrant ventral striatal responses during incentive processing in unmedicated patients with obsessive-compulsive disorder. Acta Psychiatr Scand 123:376-386. CrossRef Medline

Kalivas PW, Volkow ND (2005) The neural basis of addiction: a pathology of motivation and choice. Am J Psychiatry 162:1403-1413. CrossRef Medline 
Khemiri L, Guterstam J, Franck J, Jayaram-Lindström N (2012) Alcohol dependence associated with increased utilitarian moral judgment: a case control study. PLoS One 7:e39882. CrossRef Medline

Knutson B, Fong GW, Bennett SM, Adams CM, Hommer D (2003) A region of mesial prefrontal cortex tracks monetarily rewarding outcomes: characterization with rapid event-related fMRI. Neuroimage 18:263-272. CrossRef Medline

Knutson B, Bhanji JP, Cooney RE, Atlas LY, Gotlib IH (2008) Neural responses to monetary incentives in major depression. Biol Psychiatry 63: 686-692. CrossRef Medline

Koenigs M, Tranel D (2007) Irrational economic decision-making after ventromedial prefrontal damage: evidence from the Ultimatum Game. J Neurosci 27:951-956. CrossRef Medline

Koenigs M, Young L, Adolphs R, Tranel D, Cushman F, Hauser M, Damasio A (2007) Damage to the prefrontal cortex increases utilitarian moral judgements. Nature 446:908-911. CrossRef Medline

Koob GF, Volkow ND (2010) Neurocircuitry of addiction. Neuropsychopharmacology 35:217-238. CrossRef Medline

Levy DJ, Glimcher PW (2012) The root of all value: a neural common currency for choice. Curr Opin Neurobiol 22:1027-1038. CrossRef Medline

Liu X, Hairston J, Schrier M, Fan J (2011) Common and distinct networks underlying reward valence and processing stages: a meta-analysis of functional neuroimaging studies. Neurosci Biobehav Rev 35:1219-1236. CrossRef Medline

Louie K, Glimcher PW (2010) Separating value from choice: delay discounting activity in the lateral intraparietal area. J Neurosci 30:54985507. CrossRef Medline

Luo S, Ainslie G, Giragosian L, Monterosso JR (2009) Behavioral and neural evidence of incentive bias for immediate rewards relative to preferencematched delayed rewards. J Neurosci 29:14820-14827. CrossRef Medline

Manohar SG, Husain M (2016) Human ventromedial prefrontal lesions alter incentivisation by reward. Cortex 76:104-120. CrossRef Medline

Morris RW, Vercammen A, Lenroot R, Moore L, Langton JM, Short B, Kulkarni J, Curtis J, O’Donnell M, Weickert CS, Weickert TW (2012) Disambiguating ventral striatum fMRI-related BOLD signal during reward prediction in schizophrenia. Mol Psychiatry 17:235, 280-289. CrossRef Medline

Nielsen MØ, Rostrup E, Wulff S, Bak N, Lublin H, Kapur S, Glenthøj B (2012) Alterations of the brain reward system in antipsychotic naive schizophrenia patients. Biol Psychiatry 71:898-905. CrossRef Medline

Okonkwo OC, Xu G, Oh JM, Dowling NM, Carlsson CM, Gallagher CL, Birdsill AC, Palotti M, Wharton W, Hermann BP, LaRue A, Bendlin BB, Rowley HA, Asthana S, Sager MA, Johnson SC (2014) Cerebral blood flow is diminished in asymptomatic middle-aged adults with maternal history of Alzheimer's disease. Cereb Cortex 24:978-988. CrossRef Medline

Park SQ, Kahnt T, Talmi D, Rieskamp J, Dolan RJ, Heekeren HR (2012) Adaptive coding of reward prediction errors is gated by striatal coupling. Proc Natl Acad Sci U S A 109:4285-4289. CrossRef Medline

Peck CJ, Jangraw DC, Suzuki M, Efem R, Gottlieb J (2009) Reward modulates attention independently of action value in posterior parietal cortex. J Neurosci 29:11182-11191. CrossRef Medline

Peters J, LaLumiere RT, Kalivas PW (2008) Infralimbic prefrontal cortex is responsible for inhibiting cocaine seeking in extinguished rats. J Neurosci 28:6046-6053. CrossRef Medline

Platt ML, Glimcher PW (1999) Neural correlates of decision variables in parietal cortex. Nature 400:233-238. CrossRef Medline

Plichta MM, Vasic N, Wolf RC, Lesch KP, Brummer D, Jacob C, Fallgatter AJ, Grön G (2009) Neural hyporesponsiveness and hyperresponsiveness during immediate and delayed reward processing in adult attention-deficit/hyperactivity disorder. Biol Psychiatry 65:7-14. CrossRef Medline

Poldrack RA (2007) Region of interest analysis for fMRI. Soc Cogn Affect Neurosci 2:67-70. CrossRef Medline

Power JD, Barnes KA, Snyder AZ, Schlaggar BL, Petersen SE (2012) Spurious but systematic correlations in functional connectivity MRI networks arise from subject motion. Neuroimage 59:2142-2154. CrossRef Medline

Pujara MS, Wolf RC, Baskaya MK, Koenigs M (2015) Ventromedial prefrontal cortex damage alters relative risk tolerance for prospective gains and losses. Neuropsychologia 79:70-75. CrossRef Medline

Richard JM, Berridge KC (2013) Prefrontal cortex modulates desire and dread generated by nucleus accumbens glutamate disruption. Biol Psychiatry 73:360-370. CrossRef Medline
Rigoard P, Buffenoir K, Jaafari N, Giot JP, Houeto JL, Mertens P, Velut S, Bataille B (2011) The accumbofrontal fasciculus in the human brain: a microsurgical anatomical study. Neurosurgery 68:1102-1111; discussion 1111. CrossRef Medline

Robinson OJ, Cools R, Carlisi CO, Sahakian BJ, Drevets WC (2012) Ventral striatum response during reward and punishment reversal learning in unmedicated major depressive disorder. Am J Psychiatry 169:152-159. CrossRef Medline

Sanfilipo MP, Benedict RH, Zivadinov R, Bakshi R (2004) Correction for intracranial volume in analysis of whole brain atrophy in multiple sclerosis: the proportion vs. residual method. Neuroimage 22:1732-1743. CrossRef Medline

Scheres A, Milham MP, Knutson B, Castellanos FX (2007) Ventral striatal hyporesponsiveness during reward anticipation in attention-deficit/hyperactivity disorder. Biol Psychiatry 61:720-724. CrossRef Medline

Scott-Van Zeeland AA, Dapretto M, Ghahremani DG, Poldrack RA, Bookheimer SY (2010) Reward processing in autism. Autism Res 3:5367. CrossRef Medline

Seo H, Barraclough DJ, Lee D (2009) Lateral intraparietal cortex and reinforcement learning during a mixed-strategy game. J Neurosci 29:72787289. CrossRef Medline

Sesack SR, Deutch AY, Roth RH, Bunney BS (1989) Topographical organization of the efferent projections of the medial prefrontal cortex in the rat: an anterograde tract-tracing study with Phaseolus vulgaris leucoagglutinin. J Comp Neurol 290:213-242. CrossRef Medline

Smith KS, Graybiel AM (2013) A dual operator view of habitual behavior reflecting cortical and striatal dynamics. Neuron 79:361-374. CrossRef Medline

Spielberger CD, Gorsuch RL, Lushene R, Vagg PR, Jacobs GA (1983) Manual for the State-Trait Anxiety Inventory. Palo Alto, CA: Consulting Psychologists.

Stillings NA, Allen GA, Estes WK (1968) Reaction time as a function of noncontingent reward magnitude. Psychonom Sci 10:337-338. CrossRef

St Onge JR, Stopper CM, Zahm DS, Floresco SB (2012) Separate prefrontalsubcortical circuits mediate different components of risk-based decision making. J Neurosci 32:2886-2899. CrossRef Medline

Stoy M, Schlagenhauf F, Sterzer P, Bermpohl F, Hägele C, Suchotzki K, Schmack K, Wrase J, Ricken R, Knutson B, Adli M, Bauer M, Heinz A, Ströhle A (2012) Hyporeactivity of ventral striatum towards incentive stimuli in unmedicated depressed patients normalizes after treatment with escitalopram. J Psychopharmacol 26:677-688. CrossRef Medline

Ströhle A, Stoy M, Wrase J, Schwarzer S, Schlagenhauf F, Huss M, Hein J, Nedderhut A, Neumann B, Gregor A, Juckel G, Knutson B, Lehmkuhl U, Bauer M, Heinz A (2008) Reward anticipation and outcomes in adult males with attention-deficit/hyperactivity disorder. Neuroimage 39:966972. CrossRef Medline

Sugrue LP, Corrado GS, Newsome WT (2004) Matching behavior and the representation of value in the parietal cortex. Science 304:1782-1787. CrossRef Medline

Tremblay LK, Naranjo CA, Graham SJ, Herrmann N, Mayberg HS, Hevenor S, Busto UE (2005) Functional neuroanatomical substrates of altered reward processing in major depressive disorder revealed by a dopaminergic probe. Arch Gen Psychiatry 62:1228-1236. CrossRef Medline

Voorn P, Vanderschuren LJ, Groenewegen HJ, Robbins TW, Pennartz CM (2004) Putting a spin on the dorsal-ventral divide of the striatum. Trends Neurosci 27:468-474. CrossRef Medline

Waltz JA, Schweitzer JB, Gold JM, Kurup PK, Ross TJ, Salmeron BJ, Rose EJ, McClure SM, Stein EA (2009) Patients with schizophrenia have a reduced neural response to both unpredictable and predictable primary reinforcers. Neuropsychopharmacology 34:1567-1577. CrossRef Medline

Watson D, Clark LA, Tellegen A (1988) Development and validation of brief measures of positive and negative affect: the PANAS scales. J Pers Soc Psychol 54:1063-1070. CrossRef Medline

Wilkinson GS, Robertson GJ (2006) WRAT4: Wide Range Achievement Test. Lutz, FL: Psychological Assessment Resources.

Xu G, Rowley HA, Wu G, Alsop DC, Shankaranarayanan A, Dowling M, Christian BT, Oakes TR, Johnson SC (2010) Reliability and precision of pseudo-continuous arterial spin labeling perfusion MRI on 3.0 T and comparison with $15 \mathrm{O}$-water PET in elderly subjects at risk for Alzheimer's disease. NMR Biomed 23:286-293. CrossRef Medline

Zald DH, Andreotti C (2010) Neuropsychological assessment of the orbital and ventromedial prefrontal cortex. Neuropsychologia 48:3377-3391. CrossRef Medline 